\title{
UWB ANTENNA WITH RECONFIGURABLE TRIPLE BAND NOTCHED CHARACTERISTICS FOR COGNITIVE RADIO
}

\author{
Anudeepa S. Kholapure ${ }^{1}$ and R.G. Karandikar ${ }^{2}$ \\ ${ }^{1}$ Department of Electronics Engineering, K.J. Somaiya College of Engineering, India \\ ${ }^{2}$ Department of Electronics and Telecommunication Engineering, K.J. Somaiya College of Engineering, India
}

\begin{abstract}
A novel printed circular monopole antenna with bandwidth more than ultra- wide band along with reconfigurable single, dual and triple notch band is presented. The antenna provides bandwidth of $3.04-17.2 \mathrm{GHz}$ by generating additional resonances towards higher end with modified ground structure. Moreover, the reconfigurable notches at WiMAX, WLAN and downlink of $X$ band satellite communication are designed using slot technique to reduce interference at these wireless services if present. Thus, designed antenna provides a good solution for spectrum sensing and dynamic spectrum access as required in cognitive radios. The reconfiguration of notch bands is experimented using $0 \mathrm{ohm}$ surface mounted resistors to show RF switching.
\end{abstract}

\section{Keywords:}

Ultra Wide Band, Reconfigurable Notches, RF Switch, Cognitive Radio, Slots

\section{INTRODUCTION}

The ultra-wideband (UWB) antennas have gain popularity as they provide larger bandwidth, high data rate wireless transmission, low power dissipation and multiple access capability. These UWB (3.1-10.6GHz) antennas finds application in cognitive radios for spectrum sensing, which is done to allocate the unused spectrum of the primary users to the secondary users for effective utilization of available spectrum. This provides solution to spectrum congestion due to increasing wireless services. But, within the ultra- wideband, there are narrow band wireless services like WiMAX (3.3-3.6GHz), lower WLAN $(5.15-5.35 \mathrm{GHz})$ and downlink of $\mathrm{X}$ band satellite communication $(7.25-7.75 \mathrm{GHz})$. This services causes interferences in the UWB spectrum. This interference is reduced by generating fixed notches at the interfering wireless services in the UWB spectrum. These fixed notches are designed by using a pair of protruded strips with the effect of mutual coupling between them [1] and split ring resonators coupled to feedline or slots etched on the radiating plane of antenna [1-2]. But, the disadvantage of the fixed notches is that they provide permanent band rejection at these wireless services and limits the full utilization of the UWB spectrum.

Instead, this paper discusses the design of frequency reconfigurable notches at these wireless services which will only be active if, interference is present from these wireless services. In addition, whenever, there is no coexistence from these services the complete UWB spectrum can be used. Thus, efficient use of spectrum is achieved by frequency agile/frequency reconfigurable antennas or wideband antenna with reconfigurable notches. [3-5] shows that antenna can select either a narrow band or wideband mode of operation depending on the reconfigurability selection. The author discusses ultra wideband antennas with reconfigurable band notch/rejection characteristics which find application for spectrum sensing and interference free spectrum allocation in cognitive radios. Hence this topic finds a great potential in research. In literature, designs of UWB with notch bands using different techniques are reported. Electronic Band Gap structures below the feedline [6] are used to create band notches which provide good gain suppression at the notches, but their performance is limited due to dielectric loss of the substrate and design complexity.

Another technique is Surface integrated waveguide cavity [7] in the feedline and has good performance but suffers due to large size and fabrication complexity of an antenna. The resonators or parasitic structures either capacitive or inductively coupled are etched in the radiating or ground or below feedline of an antenna to achieve band notches. This technique suffers due to complexity of structures and the closely space resonators shows strong couplings [8-9] which limits the maximum number of notches that can be generated. [9] Uses spiral antenna with the patch to generate Bluetooth application at $2.45 \mathrm{GHz}$ along with fixed quadruple notches in UWB by using resonators. The technique of etching slots on the antenna structure with different shapes like U, $\mathrm{E}, \mathrm{T}$ etc. are reported to achieve the band rejection [10-12]. This technique gives better performance if the effective slot length and slot position are parametrically optimised.

Most of the literature work discussed above has focussed over fixed rejection bands. But, the need of reconfigurable rejection that is presence of either or all possible combination of rejection bands arises for better spectrum sensing and the efficient allocation of the unused interference free spectrum in cognitive radios. The reconfiguration is possible by mechanical or electrical control. The author proposes the electrical control for reconfiguration of spectrum characteristics. The electrical control is done by RF switches like pin diodes, varactor diode or MEMS switches. Position of these switches on antenna determines the desired notched frequency. The reconfigurable rejection bands are created by using pin diode as switches. They are easy for biasing but have low switching speed [13-14].

Varactors diodes are used to tune the position of notch bands [15-16] by changing the capacitance value of varactor diode using applied voltage and MEMS are utilized to lower DC power consumption and fast switching time but has fabrication complexity as compared to pin diode and varactor diode [17-18]. The proposed work uses the slot technique to design compact reconfigurable triple band rejection antenna with bandwidth more than the ultra-wideband. The switches are placed at appropriate position over the slots. The switch ON/OFF state changes the current path on the surface of antenna to achieve the reconfigurable rejection bands. To the author's best knowledge the proposed antenna with reconfigurable triple band notch 
characteristics at WiMAX (3.3-3.6GHz), lower WLAN (5.15$5.35 \mathrm{GHz})$ and downlink of $X$ band satellite communication (7.25$7.75 \mathrm{GHz})$ and a bandwidth of $(3.04-17.2 \mathrm{GHz})$ is unique using slot technique.

\section{ANTENNA DESIGN AND CONFIGURATION}

The proposed antenna is a circular monopole antenna fed by a $50 \Omega$ microstrip line. Antenna is printed on FR-4 substrate $\varepsilon_{r}$ of 4.4, $\tan \delta$ of 0.02 . The antenna has a compact size of $40 \times 38 \times 1.59 \mathrm{~mm}^{3}$. In the proposed structure, a cup shaped slot is etched below the feedline and the upper edges of ground plane are cut to achieve impedance matching over a wide bandwidth. This change generates additional resonance at 12.5 and $17 \mathrm{GHz}$ which gives impedance bandwidth of (3.04-17.2GHz) with $S_{11}<-10 \mathrm{~dB}$. The Fig.1(a) shows the front view and Fig.1(b)-(d) shows the structural changes made to the ground plane to achieve large impedance bandwidth.

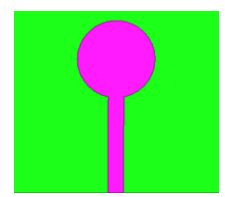

(a)

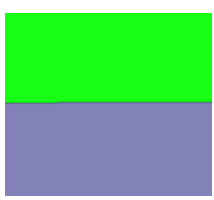

(b)

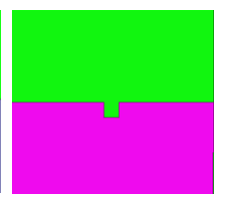

(c)

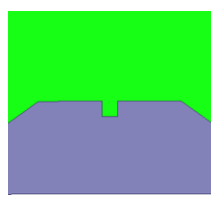

(d)
Fig.1(a). Front view Fig.1b-1d Structural changes in the ground plane to improve bandwidth

Improvements in $S_{11}$ with structural changes on the ground plane of the antenna as shown in Fig.1(b)-(d).

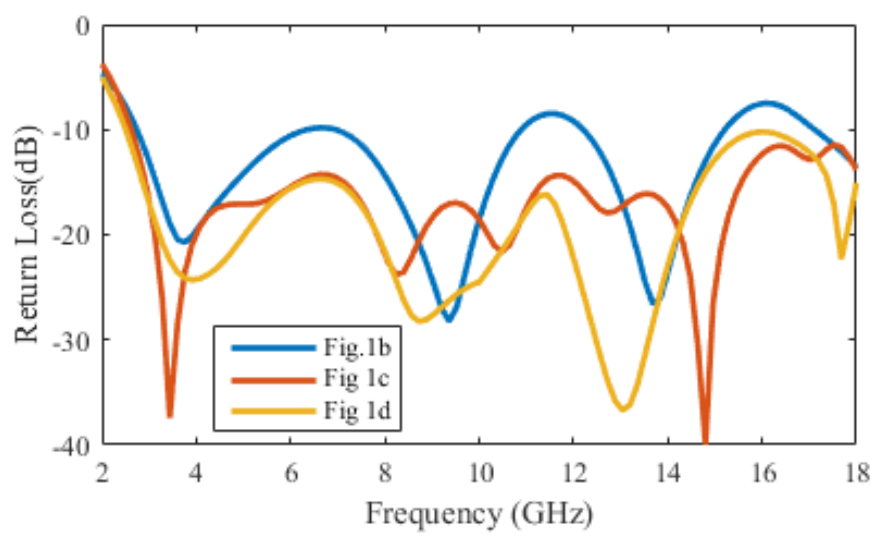

Fig.1(b)-(d). Improved bandwidth due to structural changes

The structure of the circular monopole antenna and ground plane is as shown in Fig.2(a) and Fig.2(b). The rejection bands are created by using slot technique. The two symmetrically placed open ended slots about the feedline as shown in Fig.2(b) on the ground plane are responsible to generate the stronger notch band at WiMAX. The U shaped slot in the radiating plane as shown in Fig.2(a) is responsible for rejection band at WLAN and the thin $\mathrm{U}$ slot on the ground underneath the feedline as shown in Fig.2(b) rejects the downlink frequency of $\mathrm{X}$ band satellite communication.

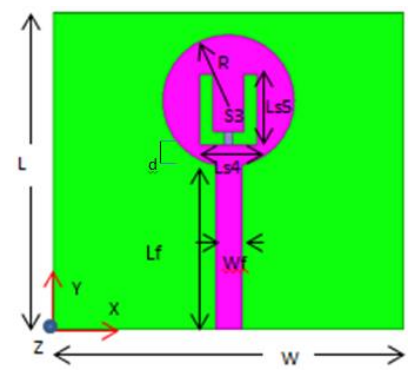

(a)

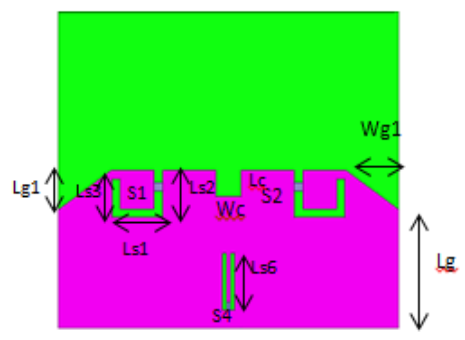

(b)

Fig.2. Geometry of the proposed antenna. (a) Front view (b) Bottom view

The effective length of the slots decides the resonant frequency of notch bands. The effective length of the open ended slot is equal to quarter of the guided wavelength at notch frequency. The effective length of $U$ shaped slots over the radiating plane and underneath the feedline is approximately half the guided wavelength at the notch frequency.

From Eq.(1) the effective lengths of the slots and practical slot lengths used in design are tabulated in Table.1,

$$
\lambda_{g}=\frac{c}{f_{0} \sqrt{\varepsilon_{\text {eff }}}}
$$

where, $\varepsilon_{\text {eff }}=\frac{1}{\varepsilon_{r}+1}$

Length of slot at respective frequencies are calculated by,

$$
\begin{gathered}
L \text { at } 3.3 \mathrm{GHz}=L s_{2}+L s_{3}+L s_{4}-g_{1} . \\
L \text { at } 5.2 \mathrm{GHz}=L s_{4}+2 L s_{5}-g_{2}-d . \\
L \text { at } 7.6 \mathrm{GHz}=2 L s_{6}-g_{3} .
\end{gathered}
$$

where, $g_{1}, g_{2}$ and $g_{3}$ are the widths of the slot respectively, $c$ is speed of light, $\varepsilon_{e f f}$ is effective dielectric constant, $\varepsilon_{r}$ is relative dielectric constant and $f_{0}$ resonant frequency for notch band.

Table.1. Optimised Dimension for Effective Resonating Length at Notch Frequency

\begin{tabular}{|c|c|c|c|c|}
\hline Slot & $\begin{array}{c}\text { Notch } \\
\text { frequency }\end{array}$ & $\begin{array}{c}\lambda g \\
(\mathbf{m m})\end{array}$ & $\begin{array}{c}\text { Slot length } \\
\text { (mm) } \\
\text { (theoretical) }\end{array}$ & $\begin{array}{c}\text { Slot length (mm) } \\
\text { (Practical) }\end{array}$ \\
\hline 1 & $3.3 \mathrm{GHz}$ & 55.32 & $\lambda \mathrm{g} / 4=13.83$ & 14.8 \\
\hline 2 & $5.2 \mathrm{GHz}$ & 35.11 & $\lambda \mathrm{g} / 2=17.55$ & 16.75 \\
\hline 3 & $7.6 \mathrm{GHz}$ & 24.02 & $\lambda \mathrm{g} / 2=12.01$ & 12.5 \\
\hline
\end{tabular}


The structure shows $S_{1}, S_{2}, S_{3}$ and $S_{4}$ are switches placed over the slot to achieve switchable rejection bands. In prototype, the RF switches are experimented by using surface mounted $0 \mathrm{ohm}$ resistor. The ON/OFF of a RF switch is experimented by the presence/absence of a $0 \mathrm{ohm}$ SMD resistor respectively. The Table.2. Shows the optimized dimension of the proposed antenna.

Table.2. Optimised Dimension of the Proposed Antenna in mm

\begin{tabular}{|c|c|c|c|}
\hline $\boldsymbol{W}$ & $\boldsymbol{L}$ & $\boldsymbol{W}_{\boldsymbol{f}}$ & $\boldsymbol{L}_{\boldsymbol{f}}$ \\
\hline 40 & 36 & 3 & 19 \\
\hline $\boldsymbol{R}$ & $\boldsymbol{L s}_{\mathbf{1}}$ & $\boldsymbol{L s}_{\mathbf{2}}$ & $\boldsymbol{L s}_{\mathbf{3}}$ \\
\hline 7.5 & 6 & 5.4 & 4.4 \\
\hline $\boldsymbol{L s}_{\mathbf{4}}$ & $\boldsymbol{L s}_{\mathbf{5}}$ & $\boldsymbol{L s}_{\mathbf{6}}$ & $\boldsymbol{L}_{\boldsymbol{c}}$ \\
\hline 6.5 & 7 & 6.6 & 3 \\
\hline $\boldsymbol{W}_{\boldsymbol{c}}$ & $\boldsymbol{W g}_{\mathbf{1}}$ & $\boldsymbol{L}_{\boldsymbol{g}}$ & $\boldsymbol{L g}_{\mathbf{1}}$ \\
\hline 3 & 6.25 & 13.5 & 4.5 \\
\hline \multicolumn{4}{|c}{$\boldsymbol{d}$} \\
\hline \multicolumn{4}{|c|}{2.25} \\
\hline
\end{tabular}

The working of the antenna can be explained using Fig.3(a)(c), when the RF switches are OFF (open) there is dominant current concentration near the slots edges at $3.6 \mathrm{GHz}, 5.2 \mathrm{GHz}$ and $7.6 \mathrm{GHz}$ notch frequencies respectively. Hence, the impedance decreases near the slots. This leads to high attenuation and hence rejection at the notch frequencies. These notch frequencies are governed by effective resonating length of the slot, their position and the width of slot is responsible for the lower frequency and bandwidth at the notch frequency. When the switches are ON (0 ohm SMD resistor connected) the current distribution remains uniform and the impedance remains matched to the feedline resulting into ultra-wide band antenna as shown in Fig.4(a).

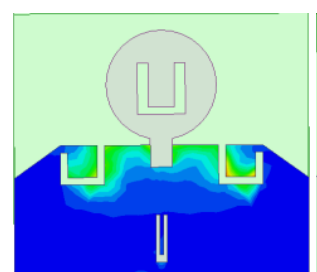

(a)

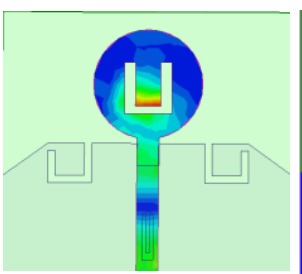

(b)

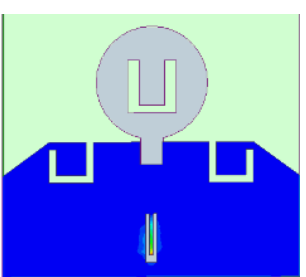

(c)
Fig.3. Simulated surface current distribution at the notch frequency (a) $3.6 \mathrm{GHz}$ (b) $5.2 \mathrm{GHz}$ (c) $7.6 \mathrm{GHz}$

\section{RESULTS AND DISCUSSION}

In this section, the simulation and measured results of return loss, gain characteristics and radiation pattern are discussed. The simulation results are obtained using High Frequency Structure Simulator (HFSS) and hardware measurements are made using vector network analyzer (VNA E8364B Agilent Technologies). The proposed antenna can work for eight states with different combinations of switches (SW1-SW2, SW3 and SW4) which generates any combination of single, dual, and triple rejection band along with UWB.

The results of return loss verses frequency of the four states for the prototype are shown below in Fig.4(a)-(d). The Fig.4(a) shows the return loss below $-10 \mathrm{~dB}$ for $3.04-17.2 \mathrm{GHz}$ which covers bandwidth of $140 \%$ more than the ultra-wideband. The Fig.4(b) for state 2 shows the rejection of WiMAX (3.3-3.6GHz) with high rejection $-2 \mathrm{~dB}$. The Fig.4(c) shows dual band rejection for WiMAX and lower WLAN $(5.15-5.35 \mathrm{GHz}$ with rejection of 2 and $-4 \mathrm{~dB}$. Additional rejection band is added in Fig.4(d) at downlink of $\mathrm{X}$ band satellite communication $(7.25-7.75 \mathrm{GHz})$ with rejection of $-5 \mathrm{~dB}$. The tolerable differences in the simulated and measured results exist because in simulation ON state is assumed as perfect E boundary in HFSS while during measurement prototype uses 0 ohm SMD resistor (0605 chip resistor) as $\mathrm{ON}$ state. The differences are more prominent at high frequency due to transit time effect in components at high frequency. Also there is difference due to fabrication and soldering of chip component as well as the connection losses between port and the antenna.

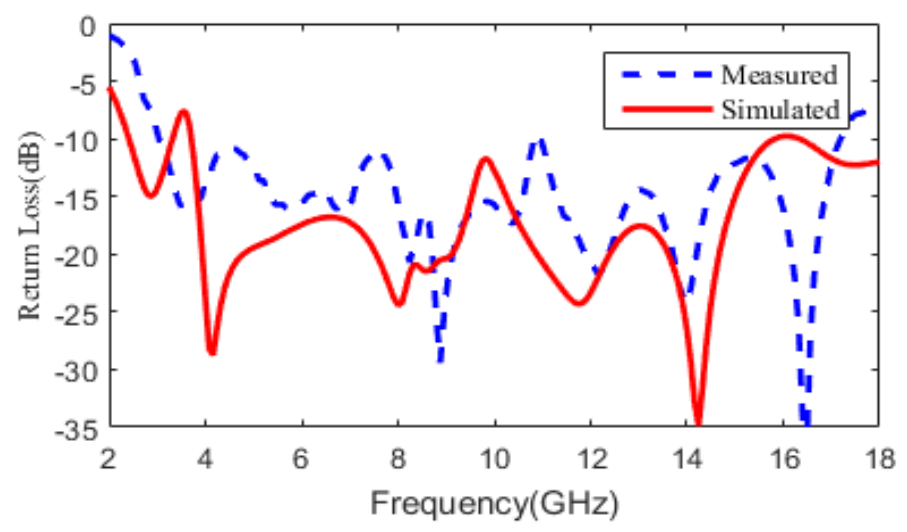

Fig.4(a). Simulated and measured results of state 1 with UWB

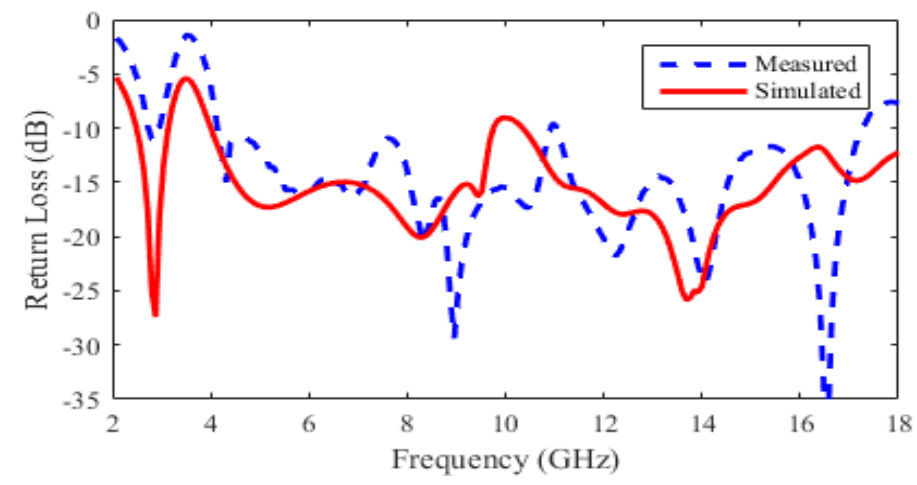

Fig.4(b). Simulated and measured results of state 2 with single notch

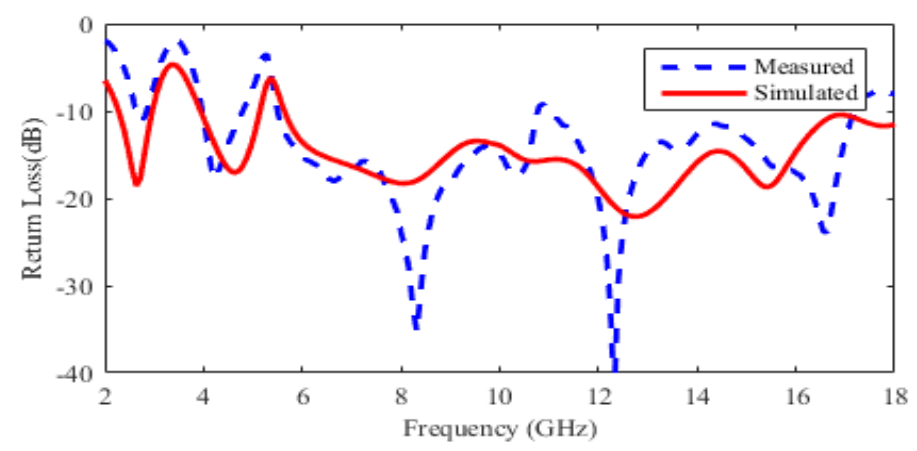

Fig.4(c). Simulated and measured results of state 3 with dual notch 


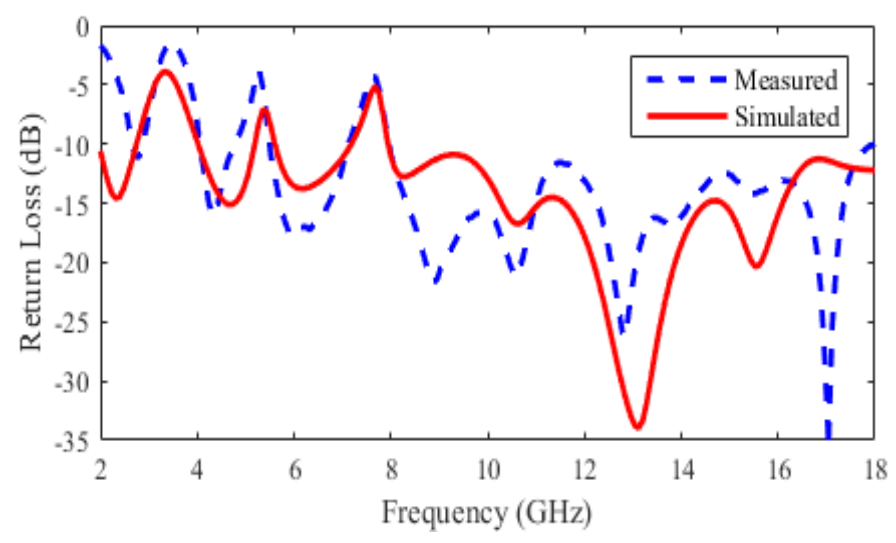

Fig.4(d). Simulated and measured results of state 4 with triple notch

The details of bandwidth of the four states along with the comparison between the simulated and measured results are tabulated in Table. 3 below.

Table.3. Simulated and Measured Return loss for Four States of the Proposed Antenna

\begin{tabular}{|c|c|c|c|c|c|c|}
\hline \multirow{3}{*}{ State } & \multicolumn{3}{|c|}{$\begin{array}{l}\text { Switch }(\text { SW) } \\
\text { Configuration }\end{array}$} & \multicolumn{3}{|c|}{ Results } \\
\hline & \multirow{2}{*}{$\begin{array}{c}\text { SW } \\
1 \& 2\end{array}$} & \multirow{2}{*}{$\begin{array}{c}\text { SW } \\
\mathbf{3}\end{array}$} & \multirow{2}{*}{$\begin{array}{c}\text { SW } \\
4\end{array}$} & \multirow{2}{*}{$\begin{array}{l}\text { No. of } \\
\text { Bands } \\
\text { Notch }\end{array}$} & \multicolumn{2}{|c|}{ Bandwidth(GHz) } \\
\hline & & & & & Simulated & Measured \\
\hline 1 & $\mathrm{ON}$ & ON & $\mathrm{ON}$ & UWB & $2.64-16.2$ & $3.04-17.2$ \\
\hline 2 & OFF & ON & $\mathrm{ON}$ & $\begin{array}{l}\text { Single } \\
\text { Notch } \\
\text { Band }\end{array}$ & $2.96-3.92$ & $2.96-4.16$ \\
\hline \multirow[b]{2}{*}{3} & \multirow[b]{2}{*}{ OFF } & \multirow[b]{2}{*}{ OFF } & \multirow[b]{2}{*}{$\mathrm{ON}$} & \multirow{2}{*}{$\begin{array}{c}\text { Dual } \\
\text { Notch } \\
\text { Band }\end{array}$} & $2.92-3.92$ & $2.96-3.92$ \\
\hline & & & & & 5.04-5.68 & $4.8-5.5$ \\
\hline \multirow{3}{*}{4} & \multirow{3}{*}{ OFF } & \multirow{3}{*}{ OFF } & \multirow{3}{*}{ OFF } & \multirow{3}{*}{$\begin{array}{l}\text { Triple } \\
\text { Notch } \\
\text { Band }\end{array}$} & $2.9-3.92$ & $2.89-4.06$ \\
\hline & & & & & $5.2-5.68$ & $4.76-5.48$ \\
\hline & & & & & $7.12-7.8$ & $7.13-7.95$ \\
\hline
\end{tabular}

The Fig.5 indicates the comparison between the gain plot for the ultra-wide band (state 1) and triple notch antenna (state 4 ). The gain is within $0-5 \mathrm{~dB}$ for all frequencies except at the notch frequencies where the gain falls below $-2 \mathrm{~dB}$.

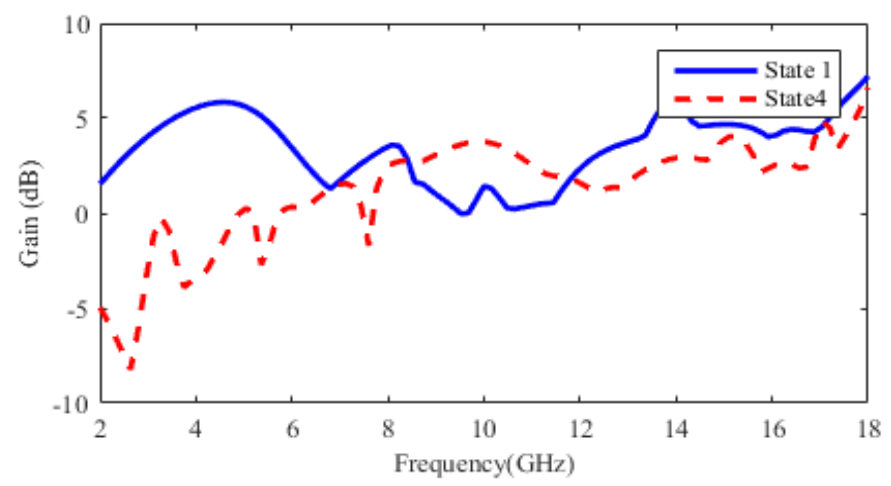

Fig.5. Simulated peak gain of antenna UWB and with triple notch bands
The Fig. 6 shows the simulated radiation pattern including Co and Cross polarization in $\mathrm{E}$ plane (yz plane) and $\mathrm{H}$ plane ( $\mathrm{xz}$ plane). The radiation patterns are omni directional both at the notch frequency and pass-band frequency showing similar radiation pattern with frequency agility which is one of the important requirement of frequency reconfigurable antennas. The cross polarization is less than co-polarization in both $\mathrm{E}$ and $\mathrm{H}$ plane. The radiation pattern remains constant over wide range of frequencies indicating that the designed antenna can be used over the wide band.

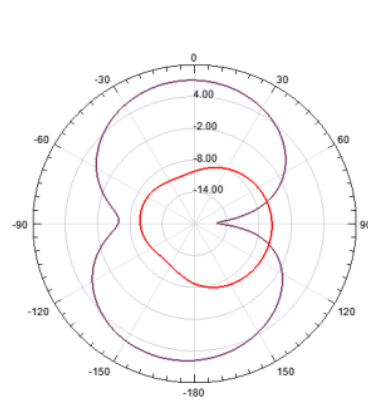

(a) E plane

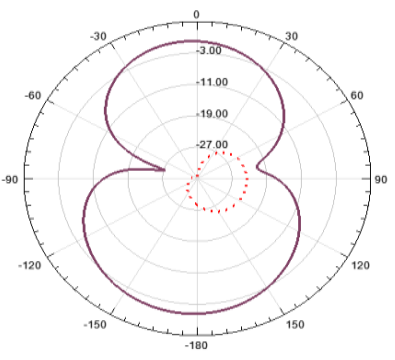

(b) E plane

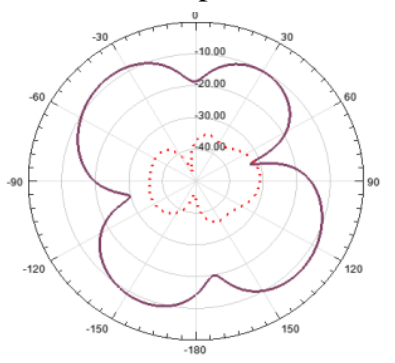

(c) E plane

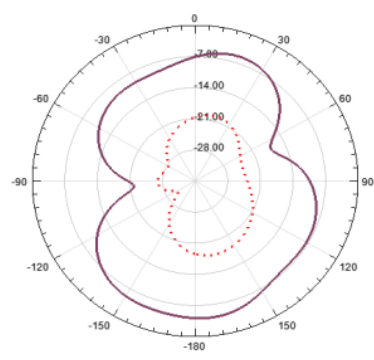

(d) E plane

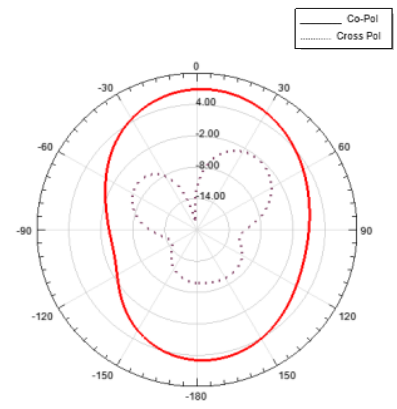

(a) H plane

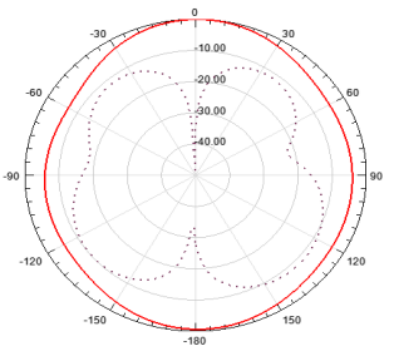

(b) H plane

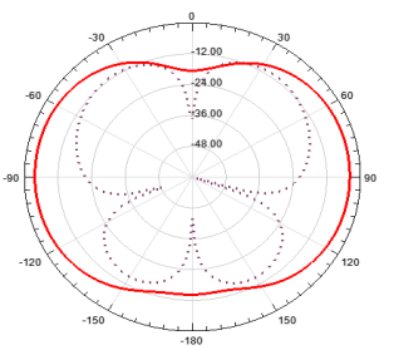

(c) H plane

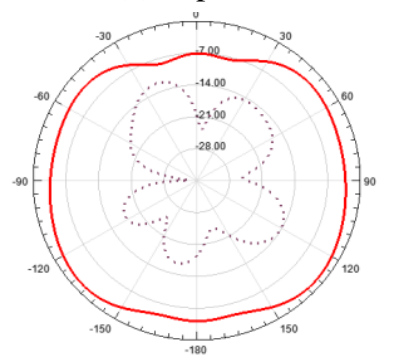

(d) H plane
Fig.6. Simulated radiation pattern of the antenna (a) $3.44 \mathrm{GHz}$ (b) $5.36 \mathrm{GHz}$ (c) $7.6 \mathrm{GHz}$ (d) $10 \mathrm{GHz}$

The Fig.7(a)-(d) shows the photograph of fabricated proposed antenna. The prototype shows the use of $0 \mathrm{ohm} \mathrm{SMD} \mathrm{resistor} \mathrm{to}$ realize an ON switch. In the prototype antenna, open circuit shows OFF switch as in Fig.7.(a)-(b) and 0 ohm SMD resistor is 
connected on the slots to realize low impedance $\mathrm{ON}$ switch as in Fig.7(c)-(d).

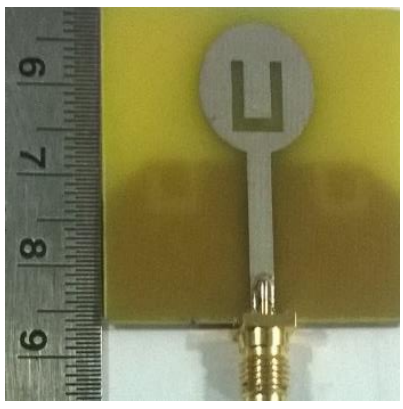

(a) Radiating plane with SW3 OFF

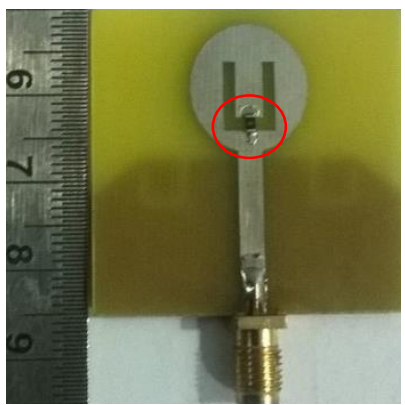

(c) Radiating plane with SW3 $\mathrm{ON}$.

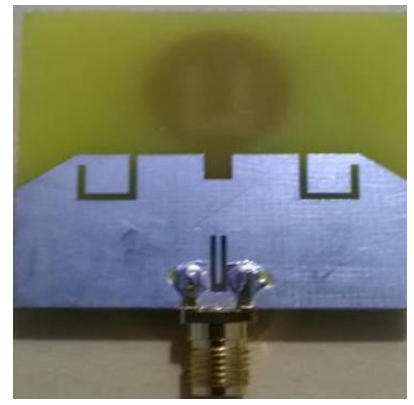

(b) Ground plane with SW1, SW2 and SW4 OFF

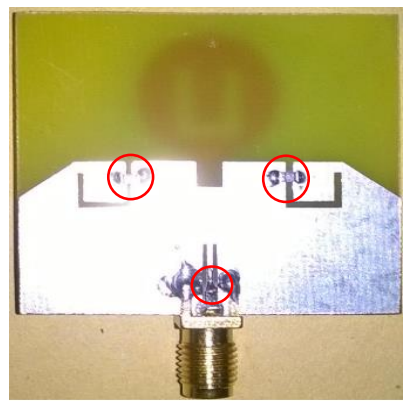

(d) Ground plane with SW1, SW2 and SW4 ON
Fig.7. Fabricated proposed antenna

Table.4. Comparisons with Reported Fixed and Reconfigurable Notch Band Antennas

\begin{tabular}{|c|c|c|c|}
\hline Ref & $\begin{array}{c}\text { Size/ } \\
\text { Material }\end{array}$ & $\begin{array}{c}\text { Rejection Bands } \\
\text { (GHz) }\end{array}$ & $\begin{array}{c}\text { BW } \\
\text { (GHz) }\end{array}$ \\
\hline 7 & $\begin{array}{c}24 \times 17 \times 0.78 \\
\mathrm{~mm}^{3} \text { Duriod } \\
\text { substrate }(2.2) \\
\tan \delta=0.0009\end{array}$ & $\begin{array}{c}\text { Fixed Bluetooth } \\
\text { Fixed Quad Rejection } \\
\text { f1 }=3.3-3.65 \mathrm{GHz} \\
\text { f2 }=5.12-5.3 \mathrm{GHz} \\
\mathrm{f} 3=5.72-5.83 \mathrm{GHz} \\
\mathrm{f} 4=8.018-8.4 \mathrm{GHz}\end{array}$ & UWB \\
\hline 11 & $\begin{array}{c}20 \times 20 \times 0.8 \mathrm{~mm}^{3} \\
\text { FR4 }\end{array}$ & $\begin{array}{c}\text { Reconfigurable single } \\
\text { and dual band } \\
\text { f1 }=3.12-3.84 \mathrm{GHz} \\
\mathrm{f} 2=4.9-6.06 \mathrm{GHz}\end{array}$ & UWB \\
\hline 13 & $\begin{array}{c}18 \times 21 \mathrm{~mm}^{2} \\
\varepsilon_{r}=4.4 \\
\text { (using varactor } \\
\text { diode) }\end{array}$ & $\begin{array}{c}\text { Triple rejection } \\
3.4-3.69 \mathrm{GHz} \\
3.4-4.2 \mathrm{GHz} \\
5.15-5.85 \mathrm{GHz} \\
\text { (single band at a time) }\end{array}$ & $\begin{array}{c}3.1-10.3 \\
\mathrm{GHz}\end{array}$ \\
\hline $\begin{array}{l}\text { Proposed } \\
\text { work }\end{array}$ & $\begin{array}{c}40 \times 38 \times 1.59 \\
\mathrm{~mm}^{3} \\
\text { FR4 }\end{array}$ & $\begin{array}{c}\text { Reconfigurable Single, dual } \\
\text { and triple notch } \\
2.89-4.06 \mathrm{GHz} \\
4.76-5.48 \mathrm{GHz} \\
7.13-7.95 \mathrm{GHz}\end{array}$ & $\begin{array}{l}3.04- \\
17.2 \\
\mathrm{GHz}\end{array}$ \\
\hline
\end{tabular}

\section{CONCLUSION}

A planar circular monopole antenna with bandwidth more than ultra-wide band (3.04-17.2GHz) with reconfigurable single, dual and triple notch band on demand using modification over the ground plane and resonating slot is designed. Thus, the designed antenna can be used for spectrum sensing and dynamic spectrum access in cognitive radios with either or all possible combination of rejection bands. Also, skillfully designed slots are simple and good solution to generate reconfigurable notches keeping small form factor without affecting other antenna parameters.

\section{ACKNOWLEDGEMENT}

The measurements on VNA E8364B Agilent Technologies were supported by the department of Atmospheric and Radar Instrumentation division at SAMEER, Mumbai.

\section{REFERENCES}

[1] M. Ojaroudi, S. Yazdanifard, N. Ojaroudi and R.A. Sadeghzadeh, "Band-Notched Small Square-Ring Antenna With a Pair of T-Shaped Strips Protruded Inside the Square Ring for UWB Applications", IEEE Antennas and Wireless Propagation Letters, Vol. 10, pp. 227-230, 2011.

[2] Y. Zhang, W. Hong, C. Yu, Z. Q. Kuai, Y.D. Don and J.Y. Zhou, "Planar Ultra wideband Antennas with Multiple Notched Bands based on Etched Slots on the Patch and/or Split Ring Resonators on the Feed Line", IEEE Transactions on Antennas and Propagation, Vol. 56, No. 9, pp. 30633068, 2008.

[3] A. Mansoul, F. Ghanem, M.R. Hamid and M. Trabelsi, "A Selective Frequency-Reconfigurable Antenna for Cognitive Radio Applications", IEEE Antennas and Wireless Propagation Letters, Vol. 13, pp. 515-518, 2014.

[4] S. Genovesi, A. Di Candia and A. Monorchio, "Compact and Low Profile Frequency Agile Antenna for Multistandard Wireless Communication Systems", IEEE Transactions on Antennas and Propagation, Vol. 62, No. 3, pp. 1019-1026, 2014.

[5] A. S. Kholapure and R.G. Karandikar, "Reconfigurable Multiband Antenna for Wi-Fi and C-Band Application", Proceedings of International Conference on Microwaves, Antennas, Propagation and Remote Sensing, pp. 16-19, 2015.

[6] H.A. Majid, M. Kamal, A. Rahim, M.R. Hamid, N.A. Murad, N.A. Samsuri, Mohd Fairus Mohd Yusof and Osman Ayop, "Reconfigurable Notched Wideband Antenna using EBG Structure", Microwave Optical Technology Letters, Vol. 57, No. 2, pp. 497-501, 2015.

[7] Y.D. Dong, W. Hong, Z.Q. Kuai, C. Yu, Y. Zhang, J.Y. Zhou and J.X. Chen, "Development of Ultrawideband Antenna with Multiple Band-Notched Characteristics using Half Mode Substrate Integrated Waveguide Cavity Technology", IEEE Transactions on Antennas and Propagation, Vol. 56, No. 9, pp. 2894-2902, 2008.

[8] S. Nikolaou, M. Davidovic, M. Nikolic and P. Vryonides, "Resonator Type and Positioning Study for the Creation of a Potentially Reconfigurable Frequency Notch in a UWB Antenna Return Loss", Proceedings of $5^{\text {th }}$ European Conference on Antennas and Propagation, pp. 350-353, 2011.

[9] G Shrikanth Reddy, A. Kamma, S.K. Mishra and J. Mukherjee, "Compact Bluetooth/UWB Dual-Band Planar Antenna with Quadruple Band-Notch Characteristics", 
IEEE Antennas and Wireless Propagation Letters, Vol. 13, pp. 872-875, 2014.

[10] M. Abdollahvand, G. Dadashzadeh and D. Mostafa, "Compact Dual Band-Notched Printed Monopole Antenna for UWB Application”, IEEE Antennas and Wireless Propagation Letters, Vol. 9, pp. 1148-1151, 2010.

[11] A.S. Kholapure and R.G. Karandikar, "Emerging Techniques for Printed Reconfigurable Antenna: A Review", Proceedings of $2^{\text {nd }}$ International Conference on Research in Computational Intelligence and Communication Networks, pp. 57-61, 2016.

[12] T.D. Nguyen, D.H. Lee and H.C. Park, "Design and Analysis of Compact Printed Triple Band-Notched UWB Antenna", IEEE Antennas and Wireless Propagation Letters, Vol. 10, pp. 403-406, 2011.

[13] N. Tasouji, J. Nourinia, C. Ghobadi and F. Tofigh, "A Novel Printed UWB Slot Antenna with Reconfigurable BandNotch Characteristics", IEEE Antennas and Wireless Propagation Letters, Vol. 12, pp. 922-925, 2013.

[14] A. Valizade, C. Ghobadi, J. Nourinia and M. Ojaroudi, "A Novel Design of Reconfigurable Slot Antenna with
Switchable Band Notch and Multiresonance Functions for UWB Applications", IEEE Antennas and Wireless Propagation Letters, Vol. 11, pp. 1166-1169, 2012.

[15] M. Nouri and S.A. Aghdam, "Reconfigurable UWB Antenna with Electrically Control for Triple on-Demand Rejection Bandwidth", Microwave Optical Technology Letters, Vol. 57, No. 8, pp. 1894-1897, 2015.

[16] X.L. Sun, S.W. Cheung and T.I. Yuk, "Generating A Reconfigurable Notch Band For Planar UWB Monopole Antennas", Microwave Optical Technology Letters, Vol. 55, No. 12, pp. 2906-2910, 2013.

[17] C. Zhang, S. Yang, H.K. Pan, A.E. Fathy, S. El-Ghazaly and V.K. Nair, "A Reconfigurable Multiband Patch Antenna for Wireless Applications using MEMS Switches", Microwave Optical Technology Letters, Vol. 51, No. 8, pp. 1892-1895, 2009.

[18] H. Rajagopalan, J.M. Kovitz and Y. Rahmat-Samii, "MEMS Reconfigurable Optimized E-Shaped Patch Antenna Design for Cognitive Radio", IEEE Antennas and Wireless Propagation Letters, Vol. 62, No. 3, pp. 1056-1064, 2014. 